\title{
Dynamic stability of moderately thick beams and frames with the use of harmonic balance and perturbation methods
}

\author{
P. OBARA ${ }^{1 *}$ and W. GILEWSKI ${ }^{2}$ \\ ${ }^{1}$ Faculty of Civil Engineering and Architecture, Kielce University of Technology, 7 Tysiąclecia Państwa Polskiego Ave., 25-314 Kielce, Poland \\ ${ }^{2}$ Faculty of Civil Engineering, Warsaw University of Technology, Armii Ludowej 16 Ave., 00-637 Warsaw, Poland
}

\begin{abstract}
The objective of this paper is to determine dynamic instability areas of moderately thick beams and frames. The effect of moderate thickness on resonance frequencies is considered, with transverse shear deformation and rotatory inertia taken into account. These relationships are investigated using the Timoshenko beam theory. Two methods, the harmonic balance method (HBM) and the perturbation method (PM) are used for analysis. This study also examines the influence of linear dumping on induced parametric vibration. Symbolic calculations are performed in the Mathematica programme environment.
\end{abstract}

Key words: Bernoulli-Euler beam theory, Timoshenko beam theory, transverse shear deformation, rotatory inertia, natural frequency, critical force, areas of instability.

\section{Introduction}

In the relevant literature, parametric vibration is often classified as the most difficult problem of linear structure dynamics which closely combines the issues of both stability and vibration (hence the name "dynamic stability"). Several important aspects of this special subject can be found in [1-4].

Some important papers have been dedicated to the dynamic stability analysis that leads to determining the parametric resonance areas for frame structures, using either the Bernoulli-Euler theory or the Timoshenko beam theory. The first approach is used for slender rods (straight lines or planes normal to the neutral beam axis remain straight and normal after deformation) [5-8] and the latter for stocky rods (the rods with small length-to-depth ratio) in which the transverse shear deformation and the rotatory inertia are involved $[9,10]$. Various aspects for Timoshenko beam theory have been investigated, for example, beams with asymmetric cross-section [11], beams excited by a sequence of moving masses [12], twisted beams $[13,14]$, beams with damping [14] and beams under tangential follower forces [15-17]. The Timoshenko beam theory can also be used to study dynamic stability of sandwich beams [18-20]. With the resonance areas identified, dynamic parameters of the system can be determined, these parameters being very sensitive to damage in structures [21-23].

Analysis of the instability phenomenon involves solving the nonlinear time varying discretized equation of motion. The most common methods used to solve this equation include harmonic balance [1, 3, 24] and multiscale methods [25], averaging method [26], discrete singular convolution [27], the homotopy perturbation method $[28,29]$ and the perturbation method (the small parameter method or the Poincaré method) [30, 31].

*e-mail: paula@tu.kielce.pl
The majority of studies reported in the literature use numerical analysis for determining resonance areas. Only a few researchers have adopted an analytical approach.

The purpose of this article is to propose two methods for determining parametric resonance areas for moderately thick beams and frames under various support conditions. These methods, never before used for this purpose, are the harmonic balance method (HBM) and the perturbation method (PM). The latter of these two methods represents a surprisingly simple tool for achieving the goal, as its results are very close to those obtained from the standard harmonic balance method which is far more troublesome in application.

An analytical approach is used to analyze simply supported moderately thick beams, and a numerical technique, based on the finite element method with the use of physical shape functions [32] is applied to other beams and frames. The analysis covers the effect of moderate thickness on resonance frequencies and the influence of type of fixing used in the beams and frames on the instability areas. For this purpose, shear deformation and rotatory inertia are taken into account. The Timoshenko beam theory is applied to examine how these factors affect resonance frequency values. The results are compared with those obtained with the Bernoulli-Euler beam theory.

In addition, the effect of linear dumping of induced parametric vibration is considered.

\section{Analysis of a simply supported beam}

The following assumptions are adopted in physical and numerical modeling:

- The beam is made of an isotropic homogenous linear elastic material with Young's modulus $E$, shear modulus $G$ and Poisson's ratio $v$. 
- The transverse cross-section of the beam is doubly symmetric with respect to the area $A$ and the moment of inertia $I$.

- The beam has uniform mass density $\rho$ per unit length.

- The central axis is a straight line.

- The shear coefficient $\kappa$ depending on the shape of cross-section is taken into account.

- The effects of transverse shear deformation and rotatory inertia are taken into account.

- Let's consider a beam of initial length $L$, axially compressed with periodic force (Fig. 1a)

$$
S(t)=S_{o}+S_{t} \cos (\theta t)
$$

where $S_{o}$ is the static component, $S_{t}$ is the amplitude and $\theta$ is the frequency of periodic force.

In Timoshenko beam theory, the section forces can be expressed by the deflection $\widetilde{w}=\widetilde{w}(x, t)$ and the rotation function $\widetilde{\varphi}=\widetilde{\varphi}(x, t)$ as follows

$$
\begin{aligned}
& \widetilde{T}=\widetilde{T}(x, t)=\frac{G A}{\kappa}\left(\frac{\partial \widetilde{w}}{\partial x}-\widetilde{\varphi}\right), \\
& \tilde{M}=\tilde{M}(x, t)=-E I \frac{\partial \widetilde{\varphi}}{\partial x} .
\end{aligned}
$$

The dynamic equilibrium on the infinitesimal element of the beam is shown in Fig. 1b. Assuming a small curvature in the current configuration and taking into account (2), one can obtain equilibrium equations in the form

$$
\left\{\begin{array}{l}
\frac{G A}{\kappa L^{2}}\left(\frac{\partial^{2} \widetilde{w}}{\partial \xi^{2}}-L \frac{\partial \widetilde{\varphi}}{\partial \xi}\right)-\frac{S(t)}{L^{2}} \frac{\partial^{2} \widetilde{w}}{\partial \xi^{2}}-A \rho \frac{\partial^{2} \widetilde{w}}{\partial t^{2}}=0, \\
-\frac{E I}{L^{2}} \frac{\partial^{2} \widetilde{\varphi}}{\partial \xi^{2}}-\frac{G A}{\kappa L}\left(\frac{\partial \widetilde{w}}{\partial \xi}-L \widetilde{\varphi}\right)+I \rho \frac{\partial^{2} \widetilde{\varphi}}{\partial t^{2}}=0,
\end{array}\right.
$$

where $\xi=x / L$ is the non-dimensional coordinate along the axis of the beam.

a)

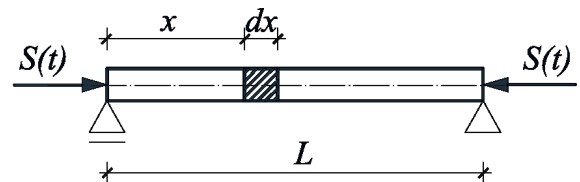

b)



Fig. 1. a) Simply supported beam, b) deformation of infinitesimal element of the beam
Equations (3) can be written as

$$
\begin{aligned}
& \frac{\partial^{4} \widetilde{w}}{\partial \xi^{4}}-\chi^{4} \zeta\left(\varepsilon^{2}+\frac{1}{n}\right) \frac{\partial^{4} \widetilde{w}}{\partial \xi^{2} \partial t^{2}}+\varepsilon^{2} \chi^{8} \zeta^{2} \frac{1}{n} \frac{\partial^{4} \widetilde{w}}{\partial t^{4}}+ \\
& +\varepsilon^{2} \sigma^{2} \frac{\partial^{2} \widetilde{w}}{\partial \xi^{2}}+\varepsilon^{2} \chi^{4} \frac{\partial^{2} \widetilde{w}}{\partial t^{2}}=0,
\end{aligned}
$$

where parameters

$$
\sigma^{2}=\frac{S L^{2}}{E I}, \quad \varepsilon^{2}=\frac{1}{1-\sigma^{2} \zeta}, \quad \chi^{4}=\frac{A \rho L^{4}}{E I}
$$

describe the geometrical and material characteristics of the beam, and parameters

$$
\zeta=\frac{n I}{A L^{2}}, \quad n=2(1+v) \kappa,
$$

include the effects of transverse shear deformation and rotatory inertia. The parameters in (6) depend only on Poisson's ratio $v$, shear coefficient $\kappa$ and slenderness ratio $\lambda=\sqrt{A L^{2} / I}$. If the parameters (6) are omitted, equation (4) becomes the equation of dynamic equilibrium in the Bernoulli-Euler beam theory.

Taking the solution to (4) in the form of the Fourier series that satisfies the boundary conditions of the simply supported beam

$$
\widetilde{w}=\sum_{k=1}^{\infty} f_{k}(t) \sin k \pi \xi ; k=1,2 \ldots
$$

On the assumption that $S_{o}=0$, equation (4), for all forms of vibration, can be written as

$$
\begin{aligned}
& \dddot{f}_{k}(t)+\omega_{k}^{2}\left(\vartheta_{k}+1-2 v \cos \theta t\right) \ddot{f}_{k}(t)+ \\
& +\omega_{k}^{4} \delta_{k}(1-2 v \cos \theta t) f_{k}(t)=0,
\end{aligned}
$$

where

$$
v=\frac{S_{t}}{2 S_{e k}}
$$

is the pulsation ratio,

$$
S_{e k}=\frac{k^{2} \pi^{2} E I}{\left(k^{2} \pi^{2} \zeta+1\right) L^{2}}, \quad \omega_{k}=\sqrt{\frac{k^{4} \pi^{4} E I}{\left(k^{2} \pi^{2} \zeta+1\right) \mu L^{4}}}
$$

are the critical force and the natural frequency of the simply supported beam with the effects of transverse shear deformation and

$$
\delta_{k}=\frac{\left(k^{2} \pi^{2} \zeta+1\right)^{2} n}{k^{4} \pi^{4} \zeta^{2}}, \quad \beta_{k}=\frac{1}{k^{2} \pi^{2} \zeta}, \quad \vartheta_{k}=\delta_{k}+\beta_{k}
$$

are the parameters dependent on the characteristics of the cross section.

Equation (8) is the differential equation with variable coefficients accounting for the transverse shear deformation and rotatory inertia of the beam. The areas of dynamic instability are determined based on (8) with the period $T$ and $2 T$, where $T=2 \pi / \theta[1,3,23]$. These areas are contained within the lines representing the pair of values, $\theta$ and $v$, characterizing the frequency of periodic force and the pulsation ratio (9). 
To solve this nonlinear problem, two approximate methods, the harmonic balance method (HBM) and the perturbation method (PM), are used.

Harmonic balance method. The first and third resonance areas. In order to determine the first and third areas of instability, it is possible to use the Fourier series with period $2 T$ for all forms of oscillation (index in the function $f$ is omitted)

$$
f(t)=\sum_{i=1,3,5 \ldots}^{\infty}\left(a_{i} \sin \frac{i \theta t}{2}+b_{i} \cos \frac{i \theta t}{2}\right),
$$

where $a_{i}$ and $b_{i}$ are constant coefficients. Substituting (12) into (8) finally gives a linear combination of trigonometric functions

$A_{1} \sin \frac{\theta t}{2}+B_{1} \cos \frac{\theta t}{2}+A_{3} \sin \frac{3 \theta t}{2}+B_{3} \cos \frac{3 \theta t}{2}+\ldots=0$,

where $A_{i}$ and $B_{i}$ are the coefficients arising after balancing the terms with appropriate harmonic

$$
\begin{aligned}
& A_{1}=\left(C_{1} a_{1}-D_{1} v a_{1}+D_{3} v a_{3}\right), \\
& A_{3}=\left(D_{1} v a_{1}+C_{3} a_{3}+D_{5} v a_{5}\right), \\
& B_{1}=\left(C_{1} b_{1}+D_{1} v b_{1}+D_{3} v b_{3}\right), \\
& B_{3}=\left(D_{1} v b_{1}+C_{3} b_{3}+D_{5} v b_{5}\right),
\end{aligned}
$$

where

$$
\begin{aligned}
& C_{i}=\left(\frac{i^{4}}{16} \eta^{4}-\frac{i^{2}}{4} \vartheta_{i} \eta^{2}-\frac{i^{2}}{4} \eta^{2}+\delta_{i}\right), \\
& D_{i}=\left(\frac{i^{2}}{4} \eta^{2}-\delta_{i}\right) ; \quad \eta=\frac{\theta}{\omega} ; \quad i=1,3,5, \ldots
\end{aligned}
$$

Equation (13) are satisfied for each $t$ provided

$$
A_{1}=B_{1}=A_{3}=B_{3}=A_{5}=\ldots=0 .
$$

Condition (16) leads to the generation of two linear separated homogenous systems with infinite equations and infinite unknowns $a_{i}$ and $b_{i}$. Solutions different from zero exist if

$$
\operatorname{det}\left\{\begin{array}{ccccc}
\left(C_{1} \pm D_{1} v\right) & D_{3} v & 0 & 0 & \ldots \\
D_{1} v & C_{3} & D_{5} v & 0 & \ldots \\
0 & D_{3} v & C_{5} & D_{7} v & \ldots \\
\ldots & \ldots & \ldots & \ldots & \ldots
\end{array}\right\}=0 .
$$

Considering the determinant of the first degree, it is sufficient to obtain the boundaries of the first area of instability

$$
C_{1} \mp D_{1} v=0 \text {, }
$$

which leads to the formula

$$
\eta_{1,2}^{2}=2\left\lfloor\vartheta_{1}+(1 \pm v) \pm \sqrt{\left(\vartheta_{1}-(1 \pm v)\right)^{2}+4 \beta_{1}(1 \pm v)}\right\rfloor .
$$

With the determinant of the second degree

$$
\left(C_{1} \mp D_{1} v\right) C_{3}-D_{1} D_{3} v^{2}=0 \text {, }
$$

the boundaries of both the first (with second approximation) and third areas of instability are determined.

The second resonance area. In order to determine the second area of instability, it is possible to use the Fourier series with period $T$

$$
f(t)=b_{0}+\sum_{i=2,4,6 \ldots}^{\infty}\left(a_{i} \sin \frac{i \theta t}{2}+b_{i} \cos \frac{i \theta t}{2}\right) .
$$

Substituting (21) into (8) gives two linear separated homogenous systems with infinite equations and infinite unknowns $a_{i}$ and $b_{i}$. Solutions different from zero exist if

$$
\operatorname{det}\left\{\begin{array}{ccccc}
C_{2} & D_{4} v & 0 & 0 & \ldots \\
D_{2} v & C_{4} & D_{6} v & 0 & \ldots \\
0 & D_{4} v & C_{6} & D_{8} v & \ldots \\
\ldots & \ldots & \ldots & \ldots & \ldots
\end{array}\right\}=0,
$$

or

$$
\operatorname{det}\left\{\begin{array}{ccccc}
\delta_{2} & D_{2} v & 0 & 0 & \ldots \\
-2 \delta_{2} v & C_{2} & D_{4} v & 0 & \ldots \\
0 & D_{2} v & C_{4} & D_{6} v & \ldots \\
\ldots & \ldots & \ldots & \ldots & \ldots
\end{array}\right\}=0
$$

To determine the boundaries of the second area of instability, it is necessary to consider at least the determinant of the second degree

$$
C_{2} C_{4}-D_{2} D_{4} v^{2}=0,\left(C_{2}+2 D_{2} v^{2}\right)=0 .
$$

The first three areas of dynamic instability are determined based on equations (18), (20) and (24).

Damping effect on the first and third resonance areas. With linear damping which causes the resistance force proportional to the speed of movement, adopted for considerations, equation (8) takes the form

$$
\begin{aligned}
& \dddot{f}_{k}(t)+2 d \dddot{f}_{k}(t)+\omega_{k}^{2}\left(\vartheta_{k}+1-2 v \cos \theta t\right) \ddot{f}_{k}(t)+ \\
& +2 d \omega_{k}^{2} \delta_{k} \dot{f}_{k}(t)+\omega_{k}^{4} \delta_{k}(1-2 v \cos \theta t) f_{k}(t)=0 ; \\
& k=1,2, \ldots,
\end{aligned}
$$

where $d=c / 2 A \rho$ is the damping coefficient and $c$ is the proportionality coefficient. The harmonic balance method using the Fourier series with period $2 T$ (12) allows computing conditions for determining the first and third areas of dynamic instability 


$$
\left(C_{1}-D_{1} v\right)\left(C_{1}+D_{1} v\right)+\left(D_{1} \frac{d}{\omega} \eta\right)^{2}=0,
$$

or

$\operatorname{det}\left\{\begin{array}{cccc}C_{3} & D_{1} v & 0 & D_{3} 3 \frac{d}{\omega} \eta \\ D_{3} v & \left(C_{1}-D_{1} v\right) & D_{1} \frac{d}{\omega} \eta & 0 \\ 0 & -D_{1} \frac{d}{\omega} \eta & \left(C_{1}+D_{1} v\right) & D_{3} v \\ -D_{3} 3 \frac{d}{\omega} \eta & 0 & D_{1} v & C_{3}\end{array}\right\}=0$.

2.2 Perturbation method. The first resonance area. In the perturbation method, a solution is found as a power series in a small parameter. Here, the pulsation ratio (9) is treated as the small parameter and the solution of equation (8) is represented as the power series

$$
f(t)=f_{0}(t)+v f_{1}(t)+v^{2} f_{2}(t)+\ldots
$$

Secular terms (increasing amplitudes of oscillation) occurring during the analysis have to be removed. For this purpose, the frequency of oscillation is assumed to depend on the small parameter

$$
\omega^{2}=\omega_{0}^{2}(v)+v \omega_{1}^{2}(v)+v^{2} \omega_{2}^{2}(v)+\ldots
$$

Substituting (28) and (29) into (8) gives an infinite recursive sequence of differential equations with constant coefficients

$v^{0}: \dddot{f_{0}}+\omega_{0}^{2}\left(\vartheta_{1}+1\right) \ddot{f}_{0}+\omega_{0}^{4} \delta_{1} f_{0}=0$,

$v^{1}: \dddot{f}_{1}+\omega_{0}^{2}\left(\vartheta_{1}+1\right) \ddot{f}_{1}+\omega_{0}^{4} \delta_{1} f_{1}=$

$\left[2 \omega_{0}^{2} \cos \theta t-\omega_{1}^{2}\left(\vartheta_{1}+1\right)\right] \ddot{f}_{0}+2 \omega_{0}^{2} \delta_{1}\left[\omega_{0}^{2} \cos \theta t-\omega_{1}^{2}\right] f_{0}$,

The small parameter method allows finding solutions for any approximation, thus any areas of instability can be attained. To determine the first area of instability, the first-order perturbation correction can be used, which involves solving equation $(30)_{2}$. By the application of auxiliary solution

$$
f_{0}=A_{0 n} \cos p_{n} \omega_{0} t+B_{0 n} \sin p_{n} \omega_{0} t ; \quad n=1,2,
$$

obtained from $(30)_{1}$, where

$$
p_{n}=\sqrt{\frac{\left(\vartheta_{1}+1\right) \pm \sqrt{\left(\vartheta_{1}+1\right)^{2}-4 \delta_{1}}}{2}}
$$

equation $(30)_{2}$ takes the form

$$
\begin{aligned}
& \dddot{f_{1}}+\omega_{0}^{2}\left(\vartheta_{1}+1\right) \ddot{f}_{1}+\omega_{0}^{4} \delta_{1} f_{1}= \\
& \omega_{0}^{4} \alpha_{1 n}\left(A_{o n} 2 \cos \Omega_{o n} t \cos \theta t+B_{o n} 2 \sin \Omega_{o n} t \cos \theta t\right)- \\
& -\omega_{0}^{2} \omega_{1}^{2} \alpha_{2 n}\left(A_{o n} \cos \Omega_{o n} t+B_{o n} \sin \Omega_{o n} t\right) ; \quad n=1,2,
\end{aligned}
$$

where

$$
\begin{aligned}
& \Omega_{o n}=p_{n} \omega_{0}, \quad \alpha_{1 n}=\delta_{1}-p_{n}^{2}, \\
& \alpha_{2 n}=p_{n}^{2}\left(\vartheta_{1}+1\right)-2 \delta_{1} ; \quad n=1,2 .
\end{aligned}
$$

Assume that the frequency of periodic force is twice the frequency of vibration. Then the solution of (33) is a function

$$
f_{1}=A_{1 n} \cos \Omega_{0 n} t+B_{1 n} \sin \Omega_{0 n} t+r_{1 S} ; \quad n=1,2,
$$

where

$$
r_{1 S}=\frac{1}{\Omega_{o n}} \int_{0}^{t} R(\tau) \sin \Omega_{o n}(t-\tau) d \tau
$$

After integration according to (36), two sets of secular terms determining the unstable nature of the solution are obtained on the right-hand side of (33). The removal of one of the terms gives a classic border solution composed of periodic functions and one secular term. The secular terms is removed as follows

$$
\alpha_{1 n} \omega_{0}^{2} \pm \alpha_{2 n} \omega_{1}^{2}=0
$$

After the substitution of $\omega_{1}$ (determined from (37)) into (29), the frequency of oscillation takes the form

$$
\omega=\omega_{0} \sqrt{1 \pm v \frac{\alpha_{1 n}}{\alpha_{2 n}}} ; \quad \alpha_{2 n} \neq 0
$$

and the first area of dynamic instability is determined based on equation

$$
\eta_{1,2}=2 p_{n} \sqrt{1 \pm v \frac{\alpha_{1 n}}{\alpha_{2 n}}}
$$

2.3 Examples. The areas of dynamic instability are determined based on (19) and (39). The areas are contained within the lines representing the pair of values $\theta$ and $v$ where $\theta$ is the frequency of periodic force and $v$ is the pulsation ratio (9). The pulsation ratio determines which part of the first critical value $S_{e}$ is the amplitude of periodic force $S_{t}$. The examples evaluate in detail the effects of the shear deformation and the rotatory inertia on the instability areas of the simply supported beam. The calculations are made in the Mathematica environment.

Example 1. In the first example, the first three areas of dynamic instability for reinforced concrete simply supported 
beam are determined using the Timoshenko and Bernoulli-Euler beam theories. In the second approach, the parameters (6) are skipped. This example illustrates the influence of the shear deformation and the rotatory inertia on the instability areas of the beam.

Let us consider a beam with a rectangular cross-section and the following geometric and mechanical characteristics: length $L=8 \mathrm{~m}$, width $b=0.5 \mathrm{~m}$, height $h=1.6$, shear factor $\kappa=1.2$, Young's modulus $E=2.7 \times 10^{10} \mathrm{~Pa}$, Poisson's ratio $v=0.2$ and mass density $\rho=2400 \mathrm{kgm}^{-3}$. The non-dimensional parameters (6) for accepted data are $\xi=0.0096$ and $n=2.88$. The results are shown in Fig. 2.

The effect of moderate thickness is the greatest on the third instability area. Areas determined using the Bernoulli-Euler beam theory (dotted line) and Timoshenko beam theory (solid line) do not have common parts (Fig. 2). In case of the first instability area, the maximum relative error between the resonance frequency values determined using the two theories is $6 \%$.

Further calculations allow determining which parameters describing the moderate thickness, shear deformation or rotatory inertia have a greater influence on resonance areas. The boundaries of the first instability area for a simply supported beam with and without the effect of rotatory inertia are determined (Fig. 3). The effect is minor because the resonance frequency is about $1.4 \%$ lower than that given without considering the rotatory inertia. In the case of the second and third areas, the effect is even smaller. Thus the rotational inertia may be omitted from the calculations.

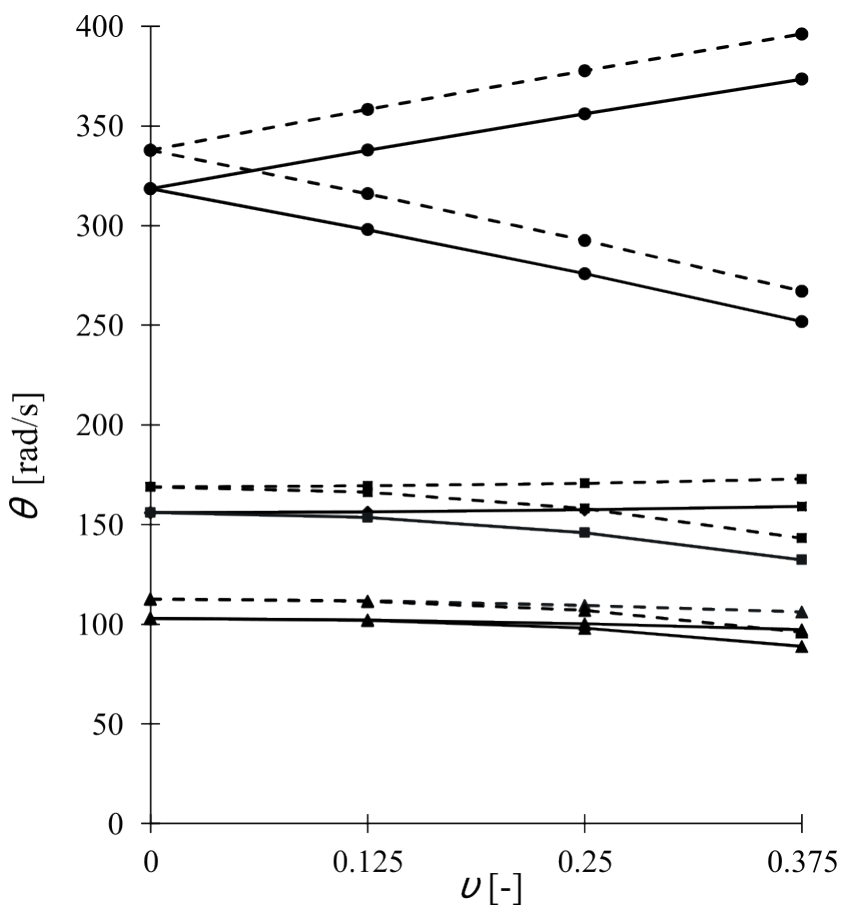

Fig. 2. First three areas of instability for simply supported beam; Bernoulli-Euler beam theory (---), Timoshenko beam theory (-); first area $(\bullet)$, second area $(\bullet)$, third area $(\boldsymbol{\Delta})$

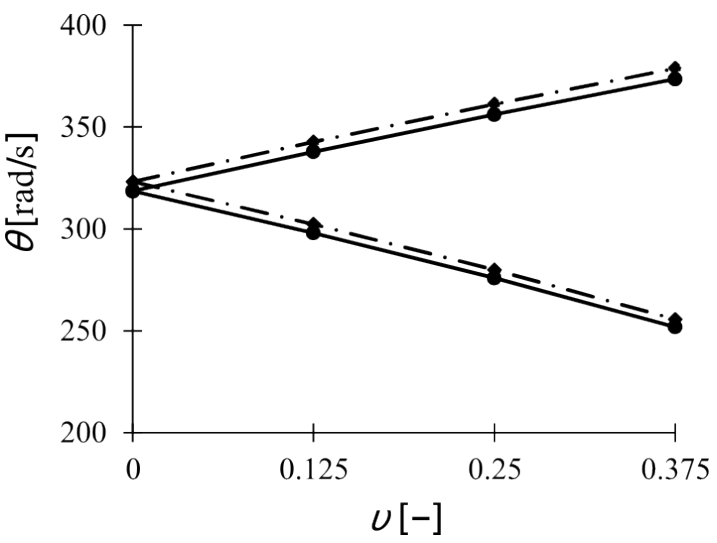

Fig. 3. Boundaries of the first instability area for simply supported beam with effect of rotatory inertia (-) and with no effect of rotatory inertia $(-\cdot-)$

Example 2. In the second example, the harmonic balance method (HBM) and perturbation method (PM) are compared. The boundaries of the first area of instability for the beam are determined from the first example. The results are shown in Table 1. The differences between the frequencies obtained by using these two methods are negligible - maximum difference is $0.0019 \mathrm{rad} / \mathrm{s}$. Since the second approach $(\mathrm{PM})$ gives a simpler formula (39), the perturbation method is proposed for determining the resonance areas.

Table 1

Resonance frequency of periodic force for simply supported beam. Comparison of two methods

\begin{tabular}{|c|c|c|c|c|c|c|}
\hline \multirow[t]{2}{*}{$v[-]$} & MBH & MMP & \multirow{2}{*}{$\begin{array}{l}\text { diffe- } \\
\text { rence } \\
[\mathrm{rad} / \mathrm{s}]]\end{array}$} & MBH & MMP & \multirow{2}{*}{$\begin{array}{c}\text { diffe- } \\
\text { rence } \\
[\mathrm{rad} / \mathrm{s}]]\end{array}$} \\
\hline & $\begin{array}{c}\theta_{1} \\
{[\mathrm{rad} / \mathrm{s}]}\end{array}$ & $\begin{array}{c}\theta_{1} \\
{[\mathrm{rad} / \mathrm{s}]}\end{array}$ & & $\begin{array}{c}\theta_{1} \\
{[\mathrm{rad} / \mathrm{s}]}\end{array}$ & $\begin{array}{c}\theta_{1} \\
{[\mathrm{rad} / \mathrm{s}]}\end{array}$ & \\
\hline 0 & 318.5663 & 318.5663 & 0.0000 & 318.5663 & 318.5663 & 0.0000 \\
\hline 0.125 & 337.8891 & 337.8893 & 0.0002 & 297.9927 & 297.9929 & 0.0002 \\
\hline 0.25 & 356.1649 & 356.1655 & 0.0006 & 275.8888 & 275.8896 & 0.0008 \\
\hline 0.375 & 373.5473 & 373.5486 & 0.0013 & 251.8519 & 251.8539 & 0.0019 \\
\hline
\end{tabular}

Example 3. The third example express the damping effect on the first and third resonance area for the beam from the first example. It is assumed that the damping coefficient $d=\Delta \omega / 2 \pi$ ( $\Delta$ is a logarithmic decrement). Calculations are made for two values of the logarithmic decrement $\Delta=0.02$ and $\Delta=0.19$. The results indicate that the first area is most dangerous because damping moves the boundaries of instability away from the axis $\theta$. In the first case (Fig. 4a), borders of the first instability area move away from the axis $\theta$ by about $v=0.0063$, and borders of the third instability area move away from the axis $\theta$ by about $v=0.167$, with about $v=0.0597$ and $v=0.3425$, respectively, in the second case (Fig. 4b). 

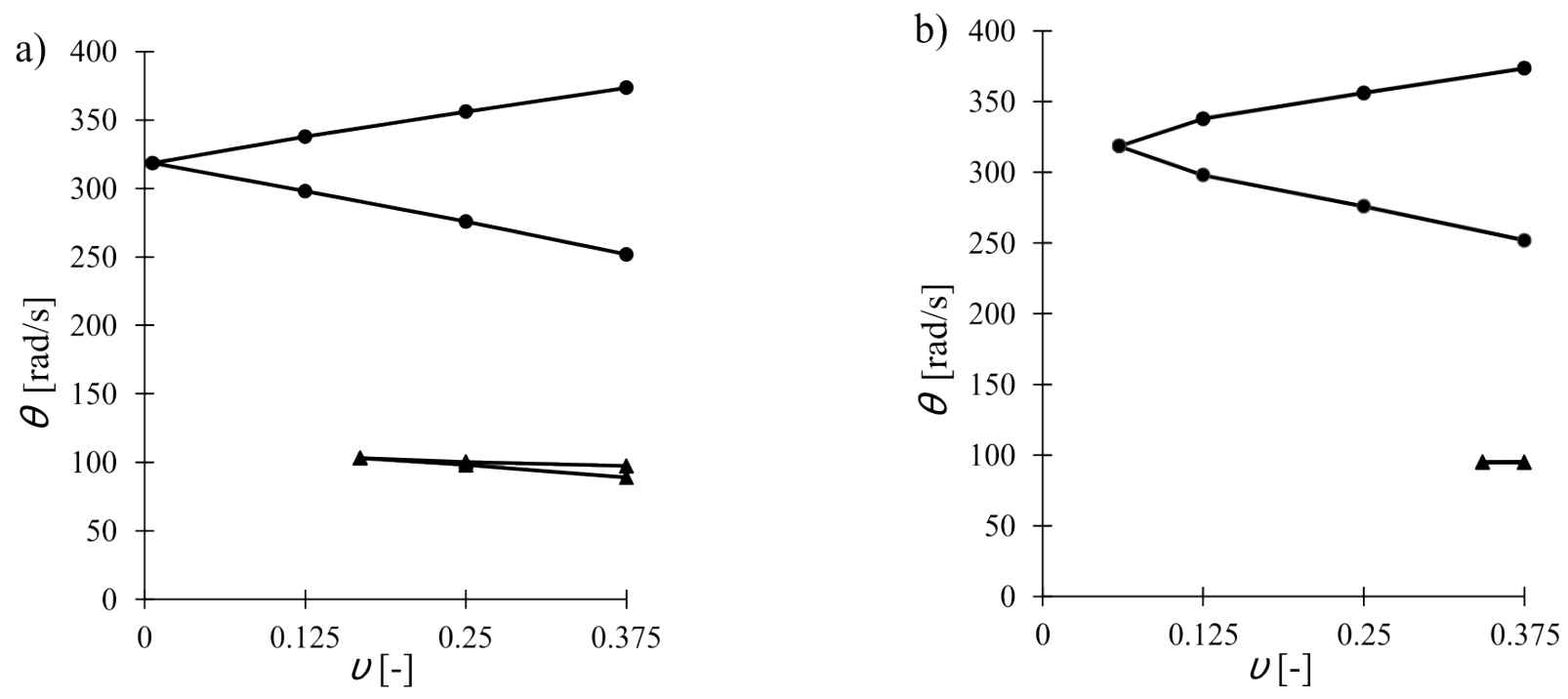

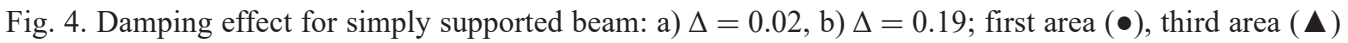

\section{Analysis of rods and frame structures}

The system of equations of motion can be written in the finite element form

$$
\left(\mathbf{M}+\mathbf{M}^{R}\right) \ddot{\mathbf{q}}(t)+\mathbf{K q}(t)-S(t) \mathbf{K}_{G} \mathbf{q}(t)=\mathbf{0},
$$

where $\mathbf{M}, \mathbf{M}^{R}, \mathbf{K}$ and $\mathbf{K}_{\mathbf{G}}$ are respectively the mass matrix, the rotatory inertia matrix, the stiffness matrix and the incremental (or geometric) stiffness matrix. These matrices include effects of the shear deformation and are developed based on physical shape functions [29].

Equation (40) allows determining the instability areas on the plane of parameters defining the load $\left(S_{0}, S_{t}, \theta\right)$ and properties of the frame structure such as the critical force $S_{e k}$ and free vibration frequency

$$
\Omega_{k}=\omega_{k} \sqrt{1-\frac{S_{o}}{S_{e k}}} ; \quad k=1,2, \ldots
$$

3.1 Harmonic balance method. To obtain the boundary frequency equations the Fourier series with period $2 T$ (12) or $T$ (21) can be used, assuming that $q(t)=f(t)$. Inserting (12) into (40) gives two linear separated homogenous systems with infinite equations and infinite unknowns $a_{i}$ and $b_{i}$. Solutions different from zero exist if

$$
\operatorname{det}\left\{\begin{array}{cccc}
\mathbf{K}-S_{0} \mathbf{K}_{G} \pm \frac{1}{2} S_{t} \mathbf{K}_{G}-\frac{1}{4} \theta^{2}\left(\mathbf{M}+\mathbf{M}^{R}\right) & -\frac{1}{2} S_{t} \mathbf{K}_{G} & 0 & \ldots \\
-\frac{1}{2} S_{t} \mathbf{K}_{G} & \mathbf{K}-S_{0} \mathbf{K}_{G}-\frac{9}{4} \theta^{2}\left(\mathbf{M}+\mathbf{M}^{R}\right) & -\frac{1}{2} S_{t} \mathbf{K}_{G} & \ldots \\
0 & -\frac{1}{2} S_{t} \mathbf{K}_{G} & \mathbf{K}-S_{0} \mathbf{K}_{G}-\frac{25}{4} \theta^{2}\left(\mathbf{M}+\mathbf{M}^{R}\right) & \ldots \\
\ldots & \ldots & \ldots & \ldots
\end{array}\right\}=0,
$$

Similar considerations for solutions with period $T$ (21) lead to two infinite equations

$$
\operatorname{det}\left\{\begin{array}{cccc}
\mathbf{K}-S_{0} \mathbf{K}_{G} & -\frac{1}{2} S_{t} \mathbf{K}_{G} & 0 & \ldots \\
-\frac{1}{2} S_{t} \mathbf{K}_{G} & \mathbf{K}-S_{0} \mathbf{K}_{G}-\theta^{2}\left(\mathbf{M}+\mathbf{M}^{R}\right) & -\frac{1}{2} S_{t} \mathbf{K}_{G} & \ldots \\
0 & -\frac{1}{2} S_{t} \mathbf{K}_{G} & \mathbf{K}-S_{0} \mathbf{K}_{G}-4 \theta^{2}\left(\mathbf{M}+\mathbf{M}^{R}\right) & \ldots \\
\ldots & \ldots & \ldots & \ldots
\end{array}\right\}=0
$$




$$
\operatorname{det}\left\{\begin{array}{ccc}
\mathbf{K}-S_{0} \mathbf{K}_{G}-\theta^{2}\left(\mathbf{M}+\mathbf{M}^{R}\right) & -\frac{1}{2} S_{t} \mathbf{K}_{G} & \ldots \\
-\frac{1}{2} S_{t} \mathbf{K}_{G} & \mathbf{K}-S_{0} \mathbf{K}_{G}-4 \theta^{2}\left(\mathbf{M}+\mathbf{M}^{R}\right) & \ldots \\
\ldots & \ldots & \ldots
\end{array}\right\}=0 .
$$

Equation (42) leads to determining first, third, fifth etc. resonance areas while equations (43) and (44) - second, fourth etc. To determine the boundaries of the first area of instability, it is necessary to consider the determinant of the first degree of matrix (42)

$$
\operatorname{det}\left(\mathbf{K}-S_{0} \mathbf{K}_{G} \pm \frac{1}{2} S_{t} \mathbf{K}_{G}-\frac{1}{4} \theta^{2}\left(\mathbf{M}+\mathbf{M}^{R}\right)\right)=0 .
$$

Equation (45) is the basis for determining the resonance frequency $\theta$ for the given $S_{o}$ and $S_{t}$.

3.2 Perturbation method. A displacement vector $\mathbf{q}(t)$ is expressed in terms of the principal coordinates $\mathbf{r}(t)$

$$
\mathbf{q}(t)=\mathbf{V r}(t),
$$

where $\mathbf{V}=\left[\begin{array}{llll}\mathbf{v}_{1} & \mathbf{v}_{2} & \ldots & \mathbf{v}_{n}\end{array}\right]$ is the modal transformation matrix composed of $\mathrm{M}$-orthonormal eigenvectors - eigenvectors are multiplied by

$$
\alpha_{k}=\frac{\sqrt{m_{o}}}{\sqrt{\mathbf{a}_{k}^{T}\left(\mathbf{M}+\mathbf{M}^{R}\right) \mathbf{a}_{k}}} ; \quad k=1,2, \ldots,
$$

where $m_{o}=1$ in the unit of mass. The modal transformation matrix has the following properties:

$$
\begin{aligned}
& \mathbf{V}^{T}\left(\mathbf{M}+\mathbf{M}^{R}\right) \mathbf{V}=m_{o} \mathbf{I}, \\
& \mathbf{V}^{T}\left(\mathbf{K}-S_{0} \mathbf{K}_{\mathbf{G}}\right) \mathbf{V}=m_{o} \mathbf{\Omega}^{2},
\end{aligned}
$$

where $\boldsymbol{\Omega}^{2}=\operatorname{diag}\left[\begin{array}{llll}\Omega_{1}^{2} & \Omega_{2}^{2} & \ldots & \Omega_{n}^{2}\end{array}\right]$ is a diagonal matrix of square frequency vibration of the system determined from equation

$$
\operatorname{det}\left(\mathbf{K}-S_{0} \mathbf{K}_{G}-\Omega^{2}\left(\mathbf{M}+\mathbf{M}^{R}\right)\right)=0 .
$$

Equation (46) is used to convert the equations of motion (40) into modal equations of motion

$$
\ddot{\mathbf{r}}(t)+\left(\boldsymbol{\Omega}^{2}-\frac{S_{t}}{m_{o}} \mathbf{K}_{G}^{*} \cos \theta t\right) \mathbf{r}(t)=\mathbf{0},
$$

where $\mathbf{K}_{G}^{*}=\mathbf{V}^{T} \mathbf{K}_{G} \mathbf{V}$ is a geometric stiffness matrix with dominated diagonal terms taken into account

$$
\mathbf{K}_{G}^{*}=\operatorname{diag}\left[K_{G 1}^{*} \quad K_{G 2}^{*} \quad \ldots \quad K_{G n}^{*}\right] .
$$

The modal coordinate transformation decouples the coupled set of equations of motion thus they can be solved using the single Mathieu-Hill differential equation

$$
\ddot{r}_{k}+\Omega_{k}^{2}\left(1-2 v_{G k} \cos \theta t\right) r_{k}=0 ; \quad k=1,2, \ldots
$$

where

$$
v_{G k}=\frac{S_{t} K_{G k}^{*}}{2 m_{o} \Omega_{k}^{2}} .
$$

The equation (52) is true for each form of vibrations, consequently the index $k$ will be omitted in next investigations. The solutions of (52) and the frequency of oscillation (41) are represented as power series with respect of the parameter (53)

$$
\begin{aligned}
& r=r_{0}(t)+v_{G} r_{1}(t)+v_{G}^{2} r_{2}(t)+\ldots, \\
& \Omega^{2}=\Omega_{0}^{2}\left(v_{G}\right)+v_{G} \Omega_{1}^{2}\left(v_{G}\right)+v_{G}^{2} \Omega_{2}^{2}\left(v_{G}\right)+\ldots .
\end{aligned}
$$

Substituting (54) to (52) and omitting higher order terms gives the infinite recursive sequence of differential equations with constant coefficients

$$
\begin{aligned}
v_{G}^{0}: & \ddot{r}_{0}+\Omega_{0}^{2} r_{0}=0, \\
v_{G}^{1}: \ddot{r}_{1}+\Omega_{0}^{2} r_{1}= & -\Omega_{1}^{2} r_{0}+2 \Omega_{0}^{2} r_{0} \cos \theta t, \\
v_{G}^{2}: \ddot{r}_{2}+\Omega_{0}^{2} r_{2}= & -\Omega_{2}^{2} r_{0}-\Omega_{1}^{2} r_{1}+ \\
& +2 \cos \theta t\left(\Omega_{1}^{2} r_{0}+\Omega_{0}^{2} r_{1}\right),
\end{aligned}
$$

Assuming that the frequency of periodic force is twice the frequency of vibration and limiting consideration to the firstorder approximation, we obtain the correction term

$$
\begin{aligned}
& \ddot{r}_{1}+\Omega_{0}^{2} r_{1}=A_{0}\left(\Omega_{0}^{2}-\Omega_{1}^{2}\right) \cos \Omega_{0} t+ \\
& -B_{0}\left(\Omega_{0}^{2}+\Omega_{1}^{2}\right) \sin \Omega_{0} t+\Omega_{0}^{2}\left(A_{0} \cos 3 \Omega_{0} t+B_{0} \sin 3 \Omega_{0} t\right) .
\end{aligned}
$$

Solution of (56) is function

$$
r_{1}=A_{1} \cos \Omega_{0} t+B_{1} \sin \Omega_{0} t+r_{1 S}
$$

where

$$
\begin{aligned}
& r_{1 S}=\frac{A_{0}\left(\Omega_{0}^{2}-\Omega_{1}^{2}\right)}{2 \Omega_{0}} t \sin \Omega_{0} t-\frac{B_{0}\left(\Omega_{0}^{2}+\Omega_{1}^{2}\right)}{2 \Omega_{0}} t \cos \Omega_{0} t+ \\
& -\frac{A_{0}}{8} \underset{(58)}{\cos 3 \Omega_{0} t-\frac{B_{0}}{8} \sin 3 \Omega_{0} t}
\end{aligned}
$$


is the particular integral. The two first terms of (58) are secular terms that determine the unstable nature of the solution. If we eliminate one of them, the classic border solution, consisting of periodic functions and one secular term, is obtained. This elimination is realized by

$$
\Omega_{0}^{2} \pm \Omega_{1}^{2}=0 \rightarrow \Omega_{1}^{2}= \pm \Omega_{0}^{2} .
$$

Condition (59) leads to the following formula

$$
\theta=2 \Omega_{0} \sqrt{1 \pm v_{G}}
$$

where $\Omega_{0}$ is the first free vibration frequency including static component of periodic force. Based on (60), we can determine the first area of dynamic instability.

3.3 Examples. The areas of dynamic instability are determined based on (45) and (60). These areas are contained within the lines representing a pair of values $\theta$ or $\eta(\eta=\theta / \omega)$ and $v$ or $S_{t} / S_{o}$, where $\omega$ is the frequency of the beam and $S_{o}$ is a static component of periodic force. Table 2 shows values of the pulsation ratio dependent on the values of the static component and amplitude of the periodic force.

Table 2

Values of amplitude of periodic force $S_{t}$ and pulsation ratio $v$ depending on values of static component of periodic force $S_{o}$

\begin{tabular}{|c|c|c|c|c|c|c|}
\hline \multirow{2}{*}{$\boldsymbol{S}_{t} / \boldsymbol{S}_{O}$} & \multicolumn{2}{|c}{$\boldsymbol{S}_{o}=\mathbf{0 . 2} \boldsymbol{S}_{e}$} & \multicolumn{2}{c}{$\boldsymbol{S}_{o}=\mathbf{0 . 5} \boldsymbol{S}_{e}$} & \multicolumn{2}{c|}{$\boldsymbol{S}_{o}=\mathbf{0 . 8} \boldsymbol{S}_{e}$} \\
\cline { 2 - 7 } & $\boldsymbol{S}_{t}$ & $\boldsymbol{v}[-]$ & $\boldsymbol{S}_{t}$ & $\boldsymbol{v}[-]$ & $\boldsymbol{S}_{t}$ & $\boldsymbol{v}[-]$ \\
\hline 0 & 0 & 0 & 0 & 0 & 0 & 0 \\
\hline 0.25 & $0.05 S_{e}$ & 0.025 & $0.125 S_{e}$ & 0.063 & $0.2 S_{e}$ & 0.1 \\
\hline 0.50 & $0.10 S_{e}$ & 0.050 & $0.250 S_{e}$ & 0.125 & $0.4 S_{e}$ & 0.2 \\
\hline 0.75 & $0.15 S_{e}$ & 0.075 & $0.375 S_{e}$ & 0.188 & $0.6 S_{e}$ & 0.3 \\
\hline 1.00 & $0.20 S_{e}$ & 0.100 & $0.500 S_{e}$ & 0.250 & $0.8 S_{e}$ & 0.4 \\
\hline
\end{tabular}

The examples show the effects of shear deformation and rotatory inertia on the instability areas of the frame structures. The calculations are performed in the Mathematica environment.

Example 1. The main resonance area of instability for a simply supported steel column with battens (Fig. 5) is determined in this example. Three cases of static component values of periodic force: $S_{o}=0.2 S_{e}, S_{o}=0.5 S_{e}$ and $S_{o}=0.8 S_{e}$ are taken into account. The following mechanical and geometric properties are chosen for the analysis:

- branches column IPE 300 (1): $I_{y}=604 \times 10^{-8} \mathrm{~m}^{4}$, $A=53.8 \times 10^{-4} \mathrm{~m}^{2}, L=2.40 \mathrm{~m}$,

- battens (2): $I_{p}=533.33 \times 10^{-8} \mathrm{~m}^{4}, A_{p}=32 \times 10^{-4} \mathrm{~m}^{2}$, $a=0.6 \mathrm{~m}, b=0.3 \mathrm{~m}, h=0.2 \mathrm{~m}, g=0.08 \mathrm{~m}$,

- the effective cross section: $I=25418 \times 10^{-8} \mathrm{~m}^{4}, \kappa=1.2$,

- Young's modulus $E=2.1 \times 10^{11} \mathrm{~Pa}$, Poisson's ratio $v=0.3$.

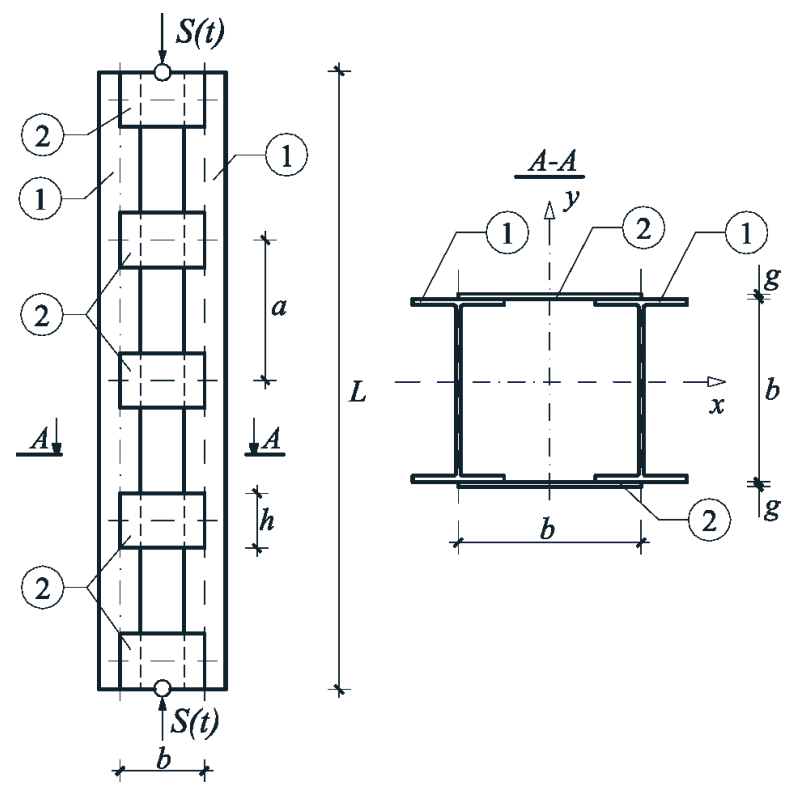

Fig. 5. Column with battens

The critical force for a column shown in Fig. 5, according to [4]

$$
S_{e}=\frac{\pi^{2} E I}{L^{2}} \frac{1}{1+\frac{\pi^{2} E I}{L^{2}}\left(\frac{a b}{12 E I_{p}}+\frac{a^{2}}{24 E I_{y}}+\frac{\kappa a}{b A_{p} G}\right)}
$$

is $S_{e}=2.2 \times 10^{7} \mathrm{~N}$. Comparison of (61) with (10) defines

$$
\zeta=\frac{E I}{L^{2}}\left(\frac{a b}{12 E I_{p}}+\frac{a^{2}}{24 E I_{y}}+\frac{\kappa a}{b A_{p} G}\right)
$$

which for the adopted data is $\xi=0.3198$.

The introduction of the effective parameter (62) allows defining the resonance areas for the column with battens. The results are shown in Fig. 6.

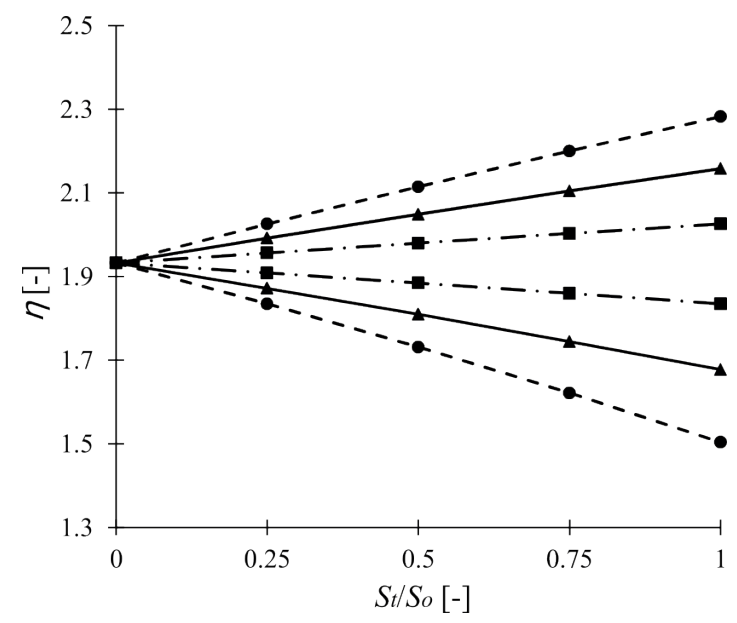

Fig. 6. First areas of instability for column showed in Fig. 5; $S_{o}=0.2 S_{e}$ $(-\cdot-), S_{o}=0.5 S_{e}(-)$, and $S_{o}=0.8 S_{e}(--)$ 



Fig. 7. Cases of analyzed beams

The field of the first instability area is largely dependent on the values of static component of periodic force. For $S_{o}=0.8 S_{e}$ the range of resonance area is more than three times larger than for $S_{o}=0.2 S_{e}$

Example 2. In the second example, boundaries of the main area of instability for beams with different support conditions (Fig. 7) are determined. The mechanical and geometric properties of the analyzed beams are the same as in chapter 2.3. Six kinds of end conditions, i.e., (a) clamped-clamped, (b) clampedhinged, (c) simply supported, (d) clamped-partly clamped, (e) cantilever beam and (f) hinged-partly clamped, are considered in this study. Calculations are carried out with beams divided into 15 finite elements. The critical forces and frequency for analyzed beams are shown in Table 3 . It is assumed that $S_{o}=0.5 S_{e}$. The results of the Timoshenko and Bernoulli-Euler beam theories are shown in Fig. 8.

Table 3

Values of critical force and frequency for beams in Fig. 7

\begin{tabular}{|c|c|c|c|c|c|c|}
\hline \multirow{2}{*}{ beam } & \multicolumn{3}{|c|}{ Timoshenko theory } & \multicolumn{2}{c|}{ Bernoulli-Euler theory } \\
\cline { 2 - 7 } & $\begin{array}{c}\boldsymbol{S}_{\boldsymbol{e}} \\
{\left[10^{8} \mathrm{~N}\right]}\end{array}$ & $\begin{array}{c}\boldsymbol{\omega}_{1} \\
{[\mathrm{rad} / \mathrm{s}]}\end{array}$ & $\begin{array}{c}\boldsymbol{\omega}_{\mathbf{1}}\left(\boldsymbol{S}_{\mathbf{0}}\right) \\
{[\mathrm{rad} / \mathrm{s}]}\end{array}$ & $\begin{array}{c}\boldsymbol{S}_{\boldsymbol{e}} \\
{\left[10^{8} \mathrm{~N}\right]}\end{array}$ & $\begin{array}{c}\boldsymbol{\omega}_{1} \\
{[\mathrm{rad} / \mathrm{s}]}\end{array}$ & $\begin{array}{c}\boldsymbol{\omega}_{\mathbf{1}}\left(\boldsymbol{S}_{\mathbf{0}}\right) \\
{[\mathrm{rad} / \mathrm{s}]}\end{array}$ \\
\hline a & 26.46 & 441.49 & 318.23 & 36.38 & 541.57 & 386.12 \\
\hline b & 15.36 & 328.06 & 234.25 & 18.60 & 373.22 & 265.55 \\
\hline c & 8.31 & 228.33 & 159.31 & 9.09 & 238.91 & 168.94 \\
\hline d & 8.31 & 127.47 & 91.27 & 9.08 & 135.39 & 96.53 \\
\hline e & 2.22 & 82.68 & 59.83 & 2.27 & 85.11 & 61.35 \\
\hline f & 2.22 & 58.80 & 41.58 & 2.27 & 59.73 & 42.23 \\
\hline
\end{tabular}

The greatest impact of shear deformation and rotatory inertia on the instability areas occurs for the clamped-clamped beam and the lowest - for the cantilever beam and the hinged-partly clamped beam. The maximum relative error between the Timoshenko theory and the Bernoulli-Euler theory, in comparison to the first one, for the clamped-clamped beam is $22 \%$, for the clamped-hinged beam is $13.5 \%$, for the simply supported beam is $6 \%$, for the clamped-partly clamped beam is $5.9 \%$, for the cantilever beam is $2.7 \%$ and for the hinged-partly clamped beam

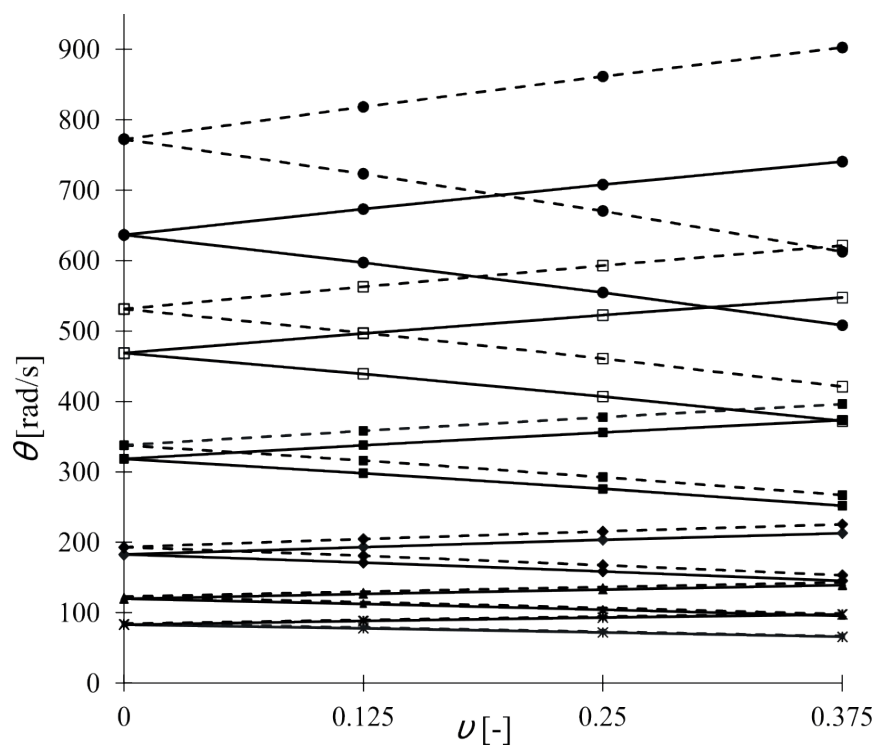

Fig. 8. First areas of instability for different beams: clamped-clamped $(\bullet)$, clamped-hinged ( $\square$ ), simply supported (₫), hinged-partly clamped $(\bullet)$, cantilever beam $(\boldsymbol{\Lambda})$ and clamped-partly clamped $(\times)$; Bernoulli-Euler beam theory (---), Timoshenko beam theory $(-)$

is $1.6 \%$. For these two last kinds of supports the Bernoulli-Euler beam theory is sufficient to determine an instability areas.

Example 3. In the third example resonance areas for reinforced concrete frames are determined. Four cases of frames (Fig. 9) are analyzed. The following mechanical and geometric properties are chosen for the analysis: $L_{1}=8.96 \mathrm{~m}, L_{2}=5.6 \mathrm{~m}$, rectangular cross-section with the width $b=0.5 \mathrm{~m}$ and height $h$ $=1.6$, shear factor $\kappa=1.2$, Young's modulus $E=2.7 \times 10^{10} \mathrm{~Pa}$, Poisson's ratio $v=0.2$ and mass density $\rho=2400 \mathrm{kgm}^{-3}$. The non-dimensional parameters (6) for the adopted data are
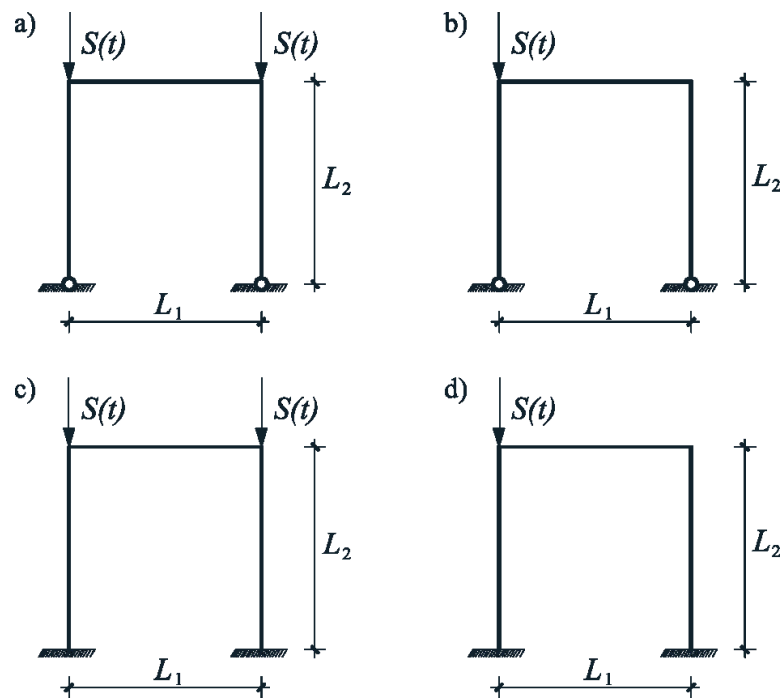

Fig. 9. Cases of analyzed frames 
$\xi_{1}=0.0076, \xi_{2}=0.0196$ and $n=2.88$. Calculations are carried out with columns and beam divided into 5 finite elements. The critical forces and frequency for the analyzed frames are shown in Table 4. It is assumed that $S_{o}=0.5 S_{e}$. The results are shown in Tables 5-8.

Table 4

Values of critical force and frequency for frames in Fig. 9

\begin{tabular}{|c|c|c|c|c|c|c|}
\hline \multirow{2}{*}{ frame } & \multicolumn{3}{|c|}{ Timoshenko theory } & \multicolumn{3}{c|}{ Bernoulli-Euler theory } \\
\cline { 2 - 7 } & $\begin{array}{c}\boldsymbol{S}_{\boldsymbol{e}} \\
{\left[10^{8} \mathrm{~N}\right]}\end{array}$ & $\begin{array}{c}\boldsymbol{\omega}_{\mathbf{1}} \\
{[\mathrm{rad} / \mathrm{s}]}\end{array}$ & $\begin{array}{c}\boldsymbol{\omega}_{\mathbf{1}}\left(\boldsymbol{S}_{\mathbf{0}}\right) \\
{[\mathrm{rad} / \mathrm{s}]}\end{array}$ & $\begin{array}{c}\boldsymbol{S}_{\boldsymbol{e}} \\
{\left[10^{8} \mathrm{~N}\right]}\end{array}$ & $\begin{array}{c}\boldsymbol{\omega}_{\mathbf{1}} \\
{[\mathrm{rad} / \mathrm{s}]}\end{array}$ & $\begin{array}{c}\boldsymbol{\omega}_{\mathbf{1}}\left(\boldsymbol{S}_{\mathbf{0}}\right) \\
{[\mathrm{rad} / \mathrm{s}]}\end{array}$ \\
\hline $\mathrm{a}$ & 2.714 & 55.31 & 39.13 & 2.89 & 57.31 & 39.24 \\
\hline $\mathrm{b}$ & 5.33 & 55.31 & 39.31 & 5.68 & 57.31 & 38.01 \\
\hline $\mathrm{c}$ & 10.46 & 116.57 & 83.07 & 12.04 & 126.43 & 76.62 \\
\hline $\mathrm{d}$ & 19.67 & 116.57 & 84.70 & 22.91 & 126.43 & 77.66 \\
\hline
\end{tabular}

Table 5

Values of resonance frequency of periodic force for frame (a)

\begin{tabular}{|l|c|c|c|c|c|c|}
\hline \multirow{2}{*}{$\boldsymbol{v}[-]$} & \multicolumn{2}{|c|}{$\begin{array}{c}\text { Timoshenko } \\
\text { with rotatory } \\
\text { inertia }\end{array}$} & \multicolumn{2}{c|}{$\begin{array}{c}\text { Timoshenko } \\
\text { without } \\
\text { rotatory inertia }\end{array}$} & \multicolumn{2}{|c|}{ Bernoulli-Euler } \\
\cline { 2 - 7 } & $\begin{array}{c}\boldsymbol{\theta}_{\mathbf{1}} \\
{[\mathbf{r a d} / \mathbf{s}]}\end{array}$ & $\begin{array}{c}\boldsymbol{\theta}_{2} \\
{[\mathbf{r a d} / \mathbf{s}]}\end{array}$ & $\begin{array}{c}\boldsymbol{\theta}_{\mathbf{1}} \\
{[\mathbf{r a d} / \mathbf{s}]}\end{array}$ & $\begin{array}{c}\boldsymbol{\theta}_{2} \\
{[\mathbf{r a d} / \mathbf{s}]}\end{array}$ & $\begin{array}{c}\boldsymbol{\theta}_{\mathbf{1}} \\
{[\mathbf{r a d} / \mathbf{s}]}\end{array}$ & $\begin{array}{c}\boldsymbol{\theta}_{2} \\
{[\mathbf{r a d} / \mathbf{s}]}\end{array}$ \\
\hline 0 & 78.26 & 78.26 & 78.48 & 78.48 & 81.09 & 81.09 \\
\hline 0.063 & 73.21 & 83.00 & 73.42 & 83.24 & 76.19 & 85.71 \\
\hline 0.125 & 67.78 & 87.48 & 67.98 & 87.74 & 70.95 & 90.09 \\
\hline 0.188 & 61.88 & 91.75 & 62.06 & 92.01 & 65.29 & 94.27 \\
\hline
\end{tabular}

Table 6

Values of resonance frequency of periodic force for frame (b)

\begin{tabular}{|l|c|c|c|c|c|c|}
\hline \multirow{2}{*}{$\boldsymbol{*}[-]$} & \multicolumn{2}{|c|}{$\begin{array}{c}\text { Timoshenko } \\
\text { with rotatory } \\
\text { inertia }\end{array}$} & \multicolumn{2}{c|}{$\begin{array}{c}\text { Timoshenko } \\
\text { without } \\
\text { rotatory inertia }\end{array}$} & \multicolumn{2}{|c|}{ Bernoulli-Euler } \\
\cline { 2 - 7 } & $\begin{array}{c}\boldsymbol{\theta}_{\mathbf{1}} \\
{[\mathbf{r a d} / \mathbf{s}]}\end{array}$ & $\begin{array}{c}\boldsymbol{\theta}_{2} \\
{[\mathbf{r a d} / \mathbf{s}]}\end{array}$ & $\begin{array}{c}\boldsymbol{\theta}_{\mathbf{1}} \\
{[\mathrm{rad} / \mathbf{s}]}\end{array}$ & $\begin{array}{c}\boldsymbol{\theta}_{2} \\
{[\mathbf{r a d} / \mathbf{s}]}\end{array}$ & $\begin{array}{c}\boldsymbol{\theta}_{\mathbf{1}} \\
{[\mathbf{r a d} / \mathbf{s}]}\end{array}$ & $\begin{array}{c}\boldsymbol{\theta}_{2} \\
{[\mathbf{r a d} / \mathbf{s}]}\end{array}$ \\
\hline 0 & 78.62 & 78.62 & 78.85 & 78.85 & 81.45 & 81.45 \\
\hline 0.063 & 73.60 & 83.34 & 73.81 & 83.58 & 76.58 & 86.05 \\
\hline 0.125 & 68.19 & 87.78 & 68.38 & 88.04 & 71.35 & 90.40 \\
\hline 0.188 & 62.29 & 92.01 & 62.47 & 92.27 & 65.70 & 94.54 \\
\hline
\end{tabular}

The influence of the rotatory inertia on the first instability area for analyzed frames is minor because the resonance frequency is about $0.3 \%$ lower than that given without considering the rotatory inertia.

The greatest impact of the shear deformation on the instability areas occurs for clamped frames $(c, d)$. The maximum relative error between the theories of Timoshenko and Bernoulli-Euler for these frames, in comparison to the first one, is about
$10.1 \%-11 \%$ (Table 5 and Table 6 ). For simply supported frames $(\mathrm{a}, \mathrm{b})$, the maximum relative error is about $5.2 \%$ (Table 7 and Table 8). The calculation shows that the impact of shear deformation on instability areas is dependent on the fixing type (as in cases of beams). The clamped fixing is more sensitive than simply supported fixing.

Table 7

Values of resonance frequency of periodic force for frame (c)

\begin{tabular}{|l|c|c|c|c|c|c|}
\hline \multirow{2}{*}{$\boldsymbol{*}[-]$} & \multicolumn{2}{|c|}{$\begin{array}{c}\text { Timoshenko } \\
\text { with rotatory } \\
\text { inertia }\end{array}$} & \multicolumn{2}{c|}{$\begin{array}{c}\text { Timoshenko } \\
\text { without } \\
\text { rotatory inertia }\end{array}$} & \multicolumn{2}{|c|}{ Bernoulli-Euler } \\
\cline { 2 - 7 } & $\begin{array}{c}\boldsymbol{\theta}_{\mathbf{1}} \\
{[\mathbf{r a d} / \mathbf{s}]}\end{array}$ & $\begin{array}{c}\boldsymbol{\theta}_{\mathbf{2}} \\
{[\mathbf{r a d} / \mathbf{s}]}\end{array}$ & $\begin{array}{c}\boldsymbol{\theta}_{\mathbf{1}} \\
{[\mathbf{r a d} / \mathbf{s}]}\end{array}$ & $\begin{array}{c}\boldsymbol{\theta}_{\mathbf{2}} \\
{[\mathbf{r a d} / \mathbf{s}]}\end{array}$ & $\begin{array}{c}\boldsymbol{\theta}_{\mathbf{1}} \\
{[\mathbf{r a d} / \mathbf{s}]}\end{array}$ & $\begin{array}{c}\boldsymbol{\theta}_{\mathbf{2}} \\
{[\mathbf{r a d} / \mathbf{s}]}\end{array}$ \\
\hline 0 & 166.14 & 166.14 & 166.63 & 166.63 & 179.86 & 179.86 \\
\hline 0.063 & 155.55 & 176.06 & 156.01 & 176.57 & 169.89 & 189.28 \\
\hline 0.125 & 144.12 & 185.40 & 144.54 & 185.94 & 159.27 & 198.23 \\
\hline 0.188 & 131.63 & 194.26 & 132.02 & 194.82 & 147.85 & 206.78 \\
\hline
\end{tabular}

Table 8

Values of resonance frequency of periodic force for frame (d)

\begin{tabular}{|c|c|c|c|c|c|c|}
\hline \multirow{2}{*}{$\boldsymbol{v}[-]$} & \multicolumn{2}{|c|}{$\begin{array}{c}\text { Timoshenko } \\
\text { with rotatory } \\
\text { inertia }\end{array}$} & \multicolumn{2}{c|}{$\begin{array}{c}\text { Timoshenko } \\
\text { without } \\
\text { rotatory inertia }\end{array}$} & \multicolumn{2}{|c|}{ Bernoulli-Euler } \\
\cline { 2 - 7 } & $\begin{array}{c}\boldsymbol{\theta}_{\mathbf{1}} \\
{[\mathbf{r a d} / \mathbf{s}]}\end{array}$ & $\begin{array}{c}\boldsymbol{\theta}_{2} \\
{[\mathrm{rad} / \mathbf{s}]}\end{array}$ & $\begin{array}{c}\boldsymbol{\theta}_{\mathbf{1}} \\
{[\mathrm{rad} / \mathbf{s}]}\end{array}$ & $\begin{array}{c}\boldsymbol{\theta}_{\mathbf{2}} \\
{[\mathrm{rad} / \mathbf{s}]}\end{array}$ & $\begin{array}{c}\boldsymbol{\theta}_{1} \\
{[\mathrm{rad} / \mathbf{s}]}\end{array}$ & $\begin{array}{c}\boldsymbol{\theta}_{2} \\
{[\mathrm{rad} / \mathbf{s}]}\end{array}$ \\
\hline 0 & 169.40 & 169.40 & 169.89 & 169.89 & 182.21 & 182.21 \\
\hline 0.063 & 159.13 & 178.96 & 159.60 & 179.48 & 172.54 & 191.32 \\
\hline 0.125 & 147.99 & 187.93 & 148.43 & 188.47 & 162.21 & 199.94 \\
\hline 0.188 & 135.74 & 196.39 & 136.15 & 196.96 & 151.08 & 208.15 \\
\hline
\end{tabular}

Another conclusion is that the influence of the shear deformation is stronger for the first frequency of periodic force $\theta_{1}$ than for the second $\theta_{2}$. For frame (c), the maximum relative error for the first frequency is about $11 \%$ and for the second $-6 \%$ (Table 7), for frame (a) $-5.2 \%$ and $2.7 \%$ (Table 5 ).

It has to be noted that the number of compression forces $S(t)$ (one or two) has a minor influence on the distribution of resonance areas. For clamped frames $(c, d)$, the maximum difference between the first frequencies is $4.11 \mathrm{rad} / \mathrm{s}$ and between the second $-2.13 \mathrm{rad} / \mathrm{s}$ (Table 5 and Table 6). For simply supported frames $(a, b)$, the difference between the first frequencies is $0.41 \mathrm{rad} / \mathrm{s}$ and between the second $-0.26 \mathrm{rad} / \mathrm{s}$ (Table 7 and Table 8).

\section{Conclusions}

The analytical approach applied in this paper to dynamic stability analysis of a simply supported moderately thick beam takes into account the influence of shear deformation and 
rotatory inertia. To illustrate this influence, Timoshenko and Bernoulli-Euler theories are used. The boundaries of the main area of instability for the beam are defined with the use of two formulas derived based on the harmonic balance method and perturbation method. The latter approach (PM) gives a simpler formula then the first one (HBM). The analysis is extended to cover the damping effect on the first and third resonance areas for the beam.

For the dynamic stability analysis of other moderately thick beams and frames, the numerical approach based on the finite element method is proposed. The matrices used in the FEM analysis, developed based on physical shape functions, include the effects of the shear deformation and the rotatory inertia. To identify the boundaries of the main resonance areas, two methods: PM and HBM are proposed.

Additionally, the effective parameter including the effect of shear deformation for a simply supported column with battens is determined (62). This allows treating these columns as beams. To determine the first resonance area, simple formulas (19) or (39) can be used.

The conclusions are as follows:

- The perturbation method is recommended for determining the first resonance area of a simply supported beam.

- The moderate thickness has the greatest effect on the third instability area.

- The first area is most dangerous because damping moves the boundaries of instability away from the axis of the resonance frequency of the periodic force.

- The effect of rotatory inertia on instability areas of frame structures is minor and can be ignored in calculations.

- The effect of shear deformation on instability areas depends on the type of fixing used. The clamped fixing is more sensitive than simply supported fixing.

\section{REFERENCES}

[1] V.V. Bołotin, Dynamic Stability of Elastic Systems, Moscow, 1956, [in Russian].

[2] A.C. Volmir, Stability of Elastic Systems, Moscow, 1963, [in Russian].

[3] M. Życzkowski, Strength of Structural Elements. Part 3: Stability of Bars and Bar Structures, Polish Scientific Publishers, Warsaw, 1991.

[4] S.P. Timoshenko and J.M. Gere, Theory of Elastic Stability, McGraw-Hill, New York, 1961.

[5] C.E. Majorana, "Dynamic stability of elastic structures: a finite element approach", Computers \& Structures 69, 11-25 (1998).

[6] W. Sochacki, "The dynamic stability of a simply supported beam with additional discrete elements", Journal of Sound and Vibration 314, 180-193 (2008).

[7] B. Sahoo, L.N. Panda, and G. Pohit, „Nonlinear dynamics of an Euler-Bernoulli beam with parametric and internal resonances”, International Conference on Design and Manufacturing, Procedia Engineering 64, 727-736 (2013).

[8] Y.Q. Huang, H.W. Lu, J.Y. Fu, A.R. Liu, and M. Gu, "Dynamic stability of Euler beams under axial unsteady wind force", Mathematical Problems in Engineering 2014, (2014).
[9] S.P. Timoshenko, "On the correction for shear of the differential equation for transverse vibrations of prismatic bars", Philosophical Magazine 41, 744-746 (1921).

[10] S.P. Timoshenko, "On the transverse vibrations of bars of uniform cross- section", Philosophical Magazine 43, 125-131 (1922).

[11] M. Sabuncu and K. Evran, "The dynamic stability of a rotating asymmetric cross-section Timoshenko beam subjected to lateral parametric excitation", Finite Elements in Analysis and Design 42, 454-469 (2006).

[12] M. Pirmoradian, M. Keshmiri, and H. Karimpour, "On the parametric excitation of a Timoshenko beam due to intermittent passage of moving masses: instability and resonance analysis", Acta Mechanica 226, 1241-1253, (2015).

[13] W.R. Chen, "Dynamic stability of linear parametrically excited twisted Timoshenko beams under periodic axial loads", Acta Mechanica 216, 207-223 (2011).

[14] W.R. Chen, "Parametric studies on bending vibration of axially-loaded twisted Timoshenko beams with locally distributed Kelvin-Voigt damping", International Journal of Mechanical Sciences 88, 61-70 (2014).

[15] B.J. Ryu, K. Katayama, and Y. Sugiyama, "Dynamic stability of Timoshenko columns subjected to subtangential forces", Computers \& Structures 68 (5), 499-512 (1998).

[16] J.H. Kim and Y.S. Choo, "Dynamic stability of a free-free Timoshenko beam subjected to a pulsating follower force", Journal of Sound and Vibration 216 (4), 623-636 (1998).

[17] P.A. Djondjorov and V.M. Vassilev, "On the dynamic stability of a cantilever under tangential follower force according to Timoshenko beam theory", Journal of Sound and Vibration 311, 1431-1437 (2008).

[18] B. Nayak, S.K., Dwivedy, and K.S.R.K. Murth, "Dynamic stability of magnetorheological elastome based adaptive sandwich beam with conductive skinsusing FEM and the harmonic balanc method", International Journal of Mechanical Sciences 77, 205-216 (2013).

[19] E. Magnucka-Blandzi, "Dynamic stability and static stress state of a sandwich beam with a metal foam core using three modified Timoshenko hypotheses", Mechanics of Advanced Materials and Structures 18, 147-158 (2011).

[20] S.C. Mohanty, R.R. Dash, and T. Rout, "Static and dynamic stability analysis of a functionally graded Timoshenko beam", International Journal of Structural Stability and Dynamics 12 (4), (2012).

[21] W.R. Chen and C.S. Chen, "Parametric instability of twisted Timoshenko beams with localized damage", International Journal of Mechanical Sciences 100, 298-311 (2015).

[22] K.H. Kim and J.H. Kim, "Effect of a crack on the dynamic stability of a free-free beam subjected to a follower force", Journal of Sound and Vibration 233 (1), 119-135 (2000).

[23] K. Dems and J. Turant, "Structural damage identification using frequency and modal changes", Bull. Pol. Ac.: Tech. 59 (1), 27-32 (2011).

[24] A. Gomuliński and M. Witkowski, Structural Mechanics. A Course for Advanced Readers, Publishing House of Warsaw University of Technology, Warsaw, 1993, [in Polish].

[25] H.P. Lee, T.H. Tan, and G.S.B. Leng, "Parametric instability of spinning pretwisted beams subjected to sinusoidal compressive axial loads", Computers \& Structures 66, 745-764 (1998).

[26] X.D. Yang, Y.Q. Tang, L.Q. Chen, and C.W. Lim, "Dynamic stability of axially accelerating Timoshenko beam: Averaging method", European Journal of Mechanics A/Solids 29, 81-90 (2010). 
[27] Z. Song, Z. Chen, W. Li, and Y. Chai, "Dynamic stability analysis of beams with shear deformation and rotary inertia subjected to periodic axial forces by using discrete singular convolution method", Journal of Engineering Mechanics 142 (3), 1-18 (2016).

[28] M. Ghomeshi Bozorg and M. Keshmiri, "Stability analysis of nonlinear time varying system of beam-moving mass considering friction interaction", Indian Journal of Science and Technology 6 (11), 5459-5468 (2013).

[29] E. Hetmaniok, D. Słota, T. Trawiński, and R. Wituła, "An analytical technique for solving general linear integral equations of the second kind and its application in analysis of flash lamp control circuit", Bull. Pol. Ac.: Tech. 62 (3), 413-421 (2014).

[30] W.J. Cunningham, Introduction to Nonlinear Analysis, McGraw-Hill, New York, 1959.

[31] M. Siwczyński and M. Jaraczewski, "The Poincare theorem in linear circuit synthesis", Bull. Pol. Ac.: Tech. (1), 49-58 (2007).

[32] W. Gilewski and A. Gomuliński, "Physical shape functions: a new concept in finite elements", Finite Elements News 3, 20-23 (1990). 